\title{
Prochazka o la forma del filósofo
}

\section{PROCHAZKA OR THE PHILOSOPHER'S FORM}

\author{
Ramiro Velaochaga Sacio \\ Universidad de Lima \\ rvelaoch@ulima.edu.pe
}

Enrique Prochazka (Lima, 1960) es un escritor peculiar, cuyos rasgos coinciden poco con lo que solemos atribuir a los intelectuales peruanos. Este filósofo-montañista (y antropólogo, carpintero, arquitecto, consultor en educación, inventor...) es autor de una obra luminosa pero compacta: apenas un puñado de títulos en treinta años (Un único desierto, 1997, reediciones en el 2007 y el 2017; la novela Casa, 2004; Cuarenta sílabas, catorce palabras, 2005, reediciones en el 2007 y el 2019; Test de Turing, publicado independientemente en el 2007, y recientemente nuevos relatos en Ocho cuentos de tampocos y todavías, 2020). Debe notarse que la aparición de cada uno de estos títulos ha sido celebrada por la crítica especializada como un hito en la narrativa nacional, y muchos de sus cuentos son considerados hoy como clásicos de la ficción peruana reciente y figuran en numerosas antologías.

En esta entrevista a cargo de otro humanista amante de las montañas y compañero de cuerda de Prochazka en múltiples aventuras - una vez le salvó la vida-, intento aprovechar su larga amistad para aproximar a los lectores a la experiencia de la escritura de ficciones filosóficas.

Eres filósofo, antropólogo, especialista en educación, fotógrafo, montañista y explorador, artesano; también, investigador y conocedor de simbología, historia, astronomía y geografía; y, por supuesto, escritor. ¿Tu literatura recoge aspectos de tus propias experiencias de esta diversidad de vida?

Empecé estudiando filosofía, pero la realización de lo que he ido aprendiendo en esa variedad de pistas que citas no está en la vida académica propiamente dicha, sino que se ha centrado en expresar experiencias de vida en términos de ficción. Es decir, en convertir experiencias que han sido principalmente personales - pero también de reflexión filosófica vital- en narrativa, en cuentos. De ese proceso surge, por ejemplo, Un único desierto. Creo que la mayor parte de los cuentos en este libro tienen algún tipo de contenido filosófico que les resulta esencial, que es su sangre. Puede haber aquí y allá un ángulo de atención a problemas filosóficos concretos que se ven en la academia, pero el aspecto vital de lo filosófico está en el centro. 


\section{Abordemos ese contraste. Cuando me hablas de la centralidad de esta o aquella cues- tión filosófica vital, ¿cómo se distingue eso de la mirada académica? ¿Por qué la ficción es tu forma preferida de tratarla?}

Bueno, miremos un ejemplo en el cuento "Happy end". Hay una pregunta muy básica en las ciencias sociales que interroga por cuál es la función de una colectividad, de una red social. Y hay una respuesta tradicional, casi formulaica: "El sentido de la existencia de una sociedad es expandir al máximo la red solidaria, reducir al mínimo las posibilidades de conflicto, y hacer la vida mejor para el mayor número posible de sus miembros". Lo que no puedo hacer en un artículo académico es llevar esa premisa a su extremo absurdo, hacer lo que se denomina un thought variant que -como lo hago en el relato- explore qué sucedería si entre las opciones para lograr el mayor bienestar posible para el mayor número de personas incluimos la más extrema, es decir, la desaparición de la especie. Máxima expansión de la red solidaria: garantizado, ya que la red incluyó a todos. Mínimas posibilidades de conflicto: garantizadas, pues nadie queda vivo para disputar nada... etcétera. Pero ¿cómo llegar a esa exploración? Pensé en que no debía tratarse de un suicidio universal, sino, de alguna manera, de un suicidio postergado mediante la no-reproducción. Así, en el cuento, la última generación de personas, los últimos hombres y mujeres, está impedida materialmente de reproducirse, pues todos nacerán estériles. De esta manera (especula el narrador) esa generación final va a ser completamente feliz, porque no tendrá que apostarle al futuro ni hacer ningún tipo de sacrificio por los hijos que nunca existirán. De esta manera, concluye el cuento, se llega a una suerte de justificación del ser por el arte. Este ejercicio de demostración por el absurdo permite, en unos pocos párrafos, llevar los dilemas sociales y del sentido de la existencia humana a su último análisis. Eso es lo que yo quería hacer con varios de los cuentos: jugar a extremar las posibilidades del análisis filosófico de una idea donde la prudencia o sobriedad académica usualmente no lo permiten.

\section{¿Y dirías que hiciste eso mismo con el primero de los cuentos, "El premio"? La historia del arquero chino que nunca falla...}

En ese cuento hay un conflicto que me parece que no se advierte con frecuencia. Es un dilema que tiene un aspecto lingüístico o, menos aún, gramatical. Atañe a la pregunta de si la realidad primordial está en el hacer o acaso en el ser; si son los verbos (las acciones) los protagonistas de la realidad o lo son las cosas. El fluido y móvil Oriente versus el Occidente firme y estable, digamos... Las dos primeras palabras del cuento, y las dos últimas, van con mayúsculas iniciales con el fin de levantar esa oposición, para hacerla formal e integrarla no solo al signo denotado, sino incluso a la estructura física del cuento. Esto ha causado algunas discusiones con editores que asumen que se trata de errores... Siempre es un ejercicio sutil este de entender qué está pensando el Otro... 
Que resulta siendo precisamente el tema de tu cuento más antologado, “Test de Turing".

Quiero creer que, pese a su aspecto de ciencia ficción y de novelita de campus universitario, "Test de Turing" es un cuento filosófico en el sentido en que se pregunta justamente en qué consiste pensar. ¿Cómo distinguir el "verdadero" pensamiento de su aspecto externo, que son las conductas y hasta los ademanes que usualmente asociamos a nuestro cuerpo cuando piensa? ¿Cómo saber si el Otro está pensando? Desde luego que no lo sabemos, y procedemos con una serie de cortesías: solo a causa de una presunción cortés, yo concedo amablemente que tú estás pensando y asumo que tú harás lo mismo conmigo. Porque podría suceder que fuera yo una máquina que está diciendo cosas sensatas y aparentemente vinculadas a "estados internos" de mi conciencia sin tenerlos, sin llevar ninguna vida interna. Eso en filosofía se llama un "zombi filosófico": un individuo que participa del mundo dialogante y reflexivo de los humanos sin ningún pensamiento propio; alguien -o más bien algo-que solo profiere cosas razonables y hasta filosóficas, pero ni las sabe, ni las siente, ni participa de ellas de manera alguna.

Todos somos "zombis filosóficos" hasta que se demuestre lo contrario...

Y justamente, como no puede demostrarse tal cosa, interviene la cortesía, que es una forma de decir que interviene la supervivencia del más apto, en una peculiar ecología de pensamientos y voluntades. Porque si el zombi tiene intenciones y tú actúas como si estas intenciones no existieran, quizá no te reproduzcas. Es mejor dar falsos positivos - por ejemplo, las cortesías de presumir que los otros tienen mente- y tener prole. La evolución nos ha dejado eso. Se llama "detección de agencia".

Claro, uno camina por la calle, compra un helado y presume que el heladero tiene una vida interna... No necesito conocer detalles de su vida o de la de sus hermanos, pero asumo que esos detalles están allí, de pleno, y le prestan contenido a su mente.

Pero en realidad no necesitas presumir eso para comprar el helado. ¿Tú presumes que la máquina que te expende una bolsa de papitas fritas en el aeropuerto tiene vida interna? Asumo que no lo supones. ¿Quién es, pues, el Otro? ¿Quién lo construye, su conducta? ¿Su aspecto? ¿Y cuánto debo considerar la vida interna del Otro, la tenga o no? Finalmente, ¿cuáles son, o serán, los derechos de esas máquinas?

En efecto, todo eso está filosóficamente apretado en ese cuento en particular. ¿Tienen los robots derecho a no ser maltratados? Es una pregunta con la que tendremos que lidiar en el plano filosófico o en el legal... Y en ese mismo plano, de suponer que existe un Otro con ciertas demandas y ciertas habilidades, acerca de los cuentos o novelas 
que has escrito (cuando estás en el acto mismo de escribirlas), ¿las haces pensando en un fin, en un buscar una reacción por parte de ese lector que "cortésmente" te lee?

Yo recuerdo con frecuencia una frase de Borges que aparece no en alguno de sus relatos, sino en una entrevista compilada por Waldemar Verdugo Fuentes. En ella afirma que es posible enseñar valentía. Dice: "No he evitado que mi obra sea pedagógica, puesto que cuando escribo situaciones épicas, estoy enseñando heroísmo a la gente". Aquel me parece un encargo precioso, muy significativo; asumí que es posible escribir de tal manera que uno consigue que el lector aprenda a realizar una virtud. No es que sea obligatorio, pero es posible. Por supuesto, existen beneficios morales de leer la vida de Jesús o incluso de leer las peripecias de los personajes de Victor Hugo, de Balzac, incluso de Dumas. Ahora bien, nunca me lo propuse como un efecto literario, sino como un reto filosófico: acercarme a la enseñanza de esa virtud concreta que menciona Borges, la valentía que hace al héroe. Finalmente, creo que es posible enseñar ética, pero la única manera de enseñar ética es con el ejemplo. Así, veo imposible ser un escritor ético si no estoy siendo, al mismo tiempo, un educador en la práctica diaria.

\section{Soledad y peligro, ¿son estos los ingredientes necesarios para la tarea del héroe?}

Bueno, eso nos remite a Joseph Campbell, de cierta manera, y a través de él a Carl Gustav Jung. Y la respuesta es que, en el marco tradicional del héroe tal como se empezó a describir ya en la Antigüedad - pienso en el análisis de la tragedia que hace Aristóteles-, el peligro adquiere la forma de un trance difícil, de un estrechamiento de las opciones, un estado angosto del ser: de allí las angustias del héroe. Ese trance no necesita ser inmediata ni actualmente peligroso; puede ser incluso continuo. Pero sí representa un riesgo existencial. La posibilidad de dejar de ser lo que es: sea porque muere o porque se transforma en algo que no es bienvenido. 0 porque esas cosas les sucederán a aquellos a quienes quiere $o$ a quienes debe defender. $Y$ allí entra el segundo tema, el de la soledad. El héroe tradicional enfrenta este trance a solas. Puede estar físicamente acompañado - Ulises y sus remeros, surcando entre las sirenas-, pero hay en su acto una soledad fundamental. Pienso también en Rolando, en Beowulf (hasta el penúltimo momento los acompañan sus queridos y fieles adláteres Turpin y Wiglaf, respectivamente), pero en ese último momento, en la fragua del mito, los amigos voltean el rostro, pues el monstruo o el enemigo va a acabar con el héroe. Porque el héroe tiene que cumplir el ciclo de pasar de héroe individual (cargado de hubris, de soberbia) a héroe social, muerto al servicio del colectivo al cual regresará, finalmente, como fantasma, pero también como leyenda. 